\title{
Isolation and Identification of Microorganisms in Eggs of a Commercial Ostrich Breeder Farm
}

\author{
Alireza Behnamifar ${ }^{1}$, Shaban Rahimi ${ }^{1}{ }^{*}$, Mohammad Ali Akhavizadegan ${ }^{2}$, Mohammad Amir Karimi Torshizi ${ }^{1}$, and Anita Maleki ${ }^{1}$ \\ ${ }^{1}$ Department of Poultry Science, Faculty of Agriculture, Tarbiat Modares University, Iran \\ ${ }^{2}$ Razi Serum and Vaccine Production Research Institute, Agriculture Research, Education and Extension Organization (AREEO), Iran
}

*Corresponding author: Shaban Rahimi, Department of Poultry Science, Faculty of Agriculture, Tarbiat Modares University, Tehran, Iran, Tel: +982148292358; E-mail: Rahimi_s@modares.ac.ir

Received: 01 Jul, 2020 | Accepted: 28 Jul, 2020 | Published: 04 Aug, 2020

Citation: Behnamifar A, Rahimi S, Akhavizadegan MA, Karimi Torshizi MA, Maleki A (2020) Isolation and Identification of Microorganisms in Eggs of a Commercial Ostrich Breeder Farm. J Anim Sci Res 4(3): dx.doi.org/10.16966/2576-6457.143

Copyright: (C) 2020 Behnamifar A, et al. This is an open-access article distributed under the terms of the Creative Commons Attribution License, which permits unrestricted use, distribution, and reproduction in any medium, provided the original author and source are credited.

\begin{abstract}
Contamination of hatching eggs with pathogenic microorganisms decrease hatchability and may cause a financial loss in industrial bird production. The aim of this study was to evaluate the microbiological status of a commercial ostrich farm and its relationship to the hatchery management. Microbial sampling was done from the organs of two dead embryos, cloacae of seven newly hatched chicks and one mature female ostrich, the content of five infertile eggs, the incubation room and incubator machines, the ingredients of diet, and the shell surface of 62 eggs which were laid during a reproductive season. Various selective and differential media included MacConkey agar, blood agar, Sabouraud's dextrose agar, nutrient agar, and PPLO agar, etc. were used for isolation and identification of the microorganisms. Different types of fungi and bacterial contamination were found on the shell surface of the eggs, which Gram-positive bacilli were isolated in $74 \%$ of these eggs (46/62). From the organs of two dead embryos Gram-positive bacilli, Gram-positive cocci, Staphylococcus epidermidis, Rhodotorula spp., Helminthosporium spp., and Aspergillus nidulans were isolated. Most of the ingredients of the diet contained Mucor spp. and a wide range of bacterial species. Finally, the effect of applying the formaldehyde gas was evaluated by McNemar's test, that results showed this method was very useful for reduction of microbial load of the eggshell in a high rate contamination. Comparison of microbial communities isolated from dead embryos and the egg-shells' surface showed that microorganisms in different parts of the farm could lead to contamination of the eggs which penetrated into the eggs. So implementing sanitation and disinfection of hatching eggs for improvement of hatchability rate is recommended.
\end{abstract}

Keywords: Bacterial and fungal contaminants; Dead embryos; Egg-shell; Incubation

\section{Introduction}

Two essential factors that demonstrate the main components of reproductive performance are fertility and hatchability [1]. Heritability of fertility and hatchability in chickens is estimated between 0.06 0.13 , so, it can be concluded that the non-genetic factors have more influence on these traits [2]. The factors that influence hatchability can be quoted as the condition of the flock (age, health, nutrition, and strain), and egg conditions such as quality, sanitation, season, size, storage duration, and weight $[3,4]$.

Attention to ostrich breeding has been increased due to the importance of ostrich products, such as meat, feathers, leather, and eggs [5]. Getting adequate profits from the breeder farms requires production high percentage of hatching egg. In the ostrich, the hatchability percentage by using the artificial incubation method is significantly lower compared with the poultry industry and reaches a maximum of about $60 \%$ on average [6]. It has been reported that the low level of hatchability of ostrich eggs in the artificial insemination is related to the presence of microbial contamination of the eggs
[7]. Deeming DC, by studying on 320 ostrich eggs from nine farms reported the average microbial contamination of $22.8 \%$ of the examined eggs [8].

Meanwhile, contamination in eggs of poultry species has been reported to be $13 \%$ on average [9]. High microbial contamination in ostrich eggs with a high percentage of weight loss during incubation indicates presence of so many pores in the ostrich egg-shells [8]. After eggs laid, the egg shell surface become contaminated with the microorganisms. If the environmental conditions are suitable, they can replicate rapidly and penetrate into the egg through the shell pores. Eventually, contamination of the egg can lead to the death of the embryo [10]. Some fungi and bacteria like pseudomonads can break down the cuticle layer. Destruction of cuticle, may cause more microorganisms enter into the egg and more moisture remove from the eggs $[10,11]$.

It has been reported by using germ-free eggs, the number of hatching eggs can be increased [12]. Therefore, for identifying sources of contamination of ostrich eggs, we tried to isolate and identify the 
microbial agents in different parts of a commercial ostrich farm, and hatchery that could contaminate ostrich eggs before a flawless incubation.

\section{Materials and Methods}

\section{Specifications of the farm}

Sampling operation to investigate microbial contamination was performed in Mohases ${ }^{ø}$ ostrich farm in Alborz Province-Iran. The farm was located in a relatively warm and dry area, and the total number of birds was around 100 Black-Necked ostriches (Struthio camelus australis). In the northern hemisphere breeding season of the ostriches starts during March and ends around August/September [13], therefore, some of the produced eggs in this period were studied for microbial contamination randomly.

In this farm, the average egg production of each laying bird per month was around nine fertilized eggs. The eggs were cleaned with a brush before being placed into the incubator machine. The farm manager believed that "it was not necessary to disinfect the eggs because the eggs were laid in the sandy nests and the ostrich is a disease-resistant bird". The farm had two setters and one hatcher machines. The hatcher and setters were cleaned and disinfected before the beginning of the breeding season. During the incubation period, an antiseptic pond was being placed in front of the entrance of the incubation room.

\section{Egg-shell sampling}

To investigate the microbial contamination of ostrich eggs, 62 eggs were sampled in the sterile plastic bags with no direct contact with hands. Isolation and identification of the germs were performed with the procedure described by Deeming DC [8]. The surface of ostrich eggs was swabbed and cultured on MacConkey agar, blood agar, Sabouraud's dextrose agar, nutrient agar and PPLO agar. Then ten eggs were fumigated with formaldehyde gas for 20 minutes in a closed container and isolation and identification of the microbes were repeated again.

\section{Environmental sampling (Incubation room: Air and Sur- face)}

Several Petri dishes containing MacConkey agar, blood agar, Sabouraud's dextrose agar, and nutrient agar were placed in the incubation room, setter and hatcher for 15 minutes. Then, they were sealed and transferred to the lab for microbial culture. Also, the air inlet and air outlet ducts were sampled by swab and were carried over to the lab [14].

\section{Dead embryos and infertile eggs sampling}

On day 38 of incubation, when the eggs were transferred to the hatcher, the eggs were candled, and five infertile eggs and two eggs with dead embryos were selected and transmitted to the laboratory in sterile bags and were pierced with a drill. After mixing their contents, sampling was done and cultured on MacConkey agar, blood agar, Sabouraud's dextrose agar, nutrient agar, and PPLO agar. The microbial contaminations were detected in two dead embryos. The samples were taken from lung, liver, intestine, eyes, yolk sac, and heart in aseptic condition. Finally, the specimens were cultured on MacConkey agar, blood agar, Sabouraud's dextrose agar, nutrient agar, and SalmonellaShigella agar $[15,16]$.

\section{Sampling of the cloaca}

Cloacae of seven newly hatched chicks and one mature female ostrich were sampled with a wet swab randomly, and specimens were cultured in selenite broth and after 24 hours were cultured on MacConkey agar and Salmonella-Shigella agar [17].

\section{Sampling of feed}

To evaluate the microbial contamination of the feed, the feed ingredients, including soybean meal, alfalfa, wheat bran, bone meal, corn, barley, and mixed diet were sampled. Samples were put in sterilized polythene packets and then transferred to the laboratory. Twenty-five g of each sample was added to $225 \mathrm{~mL}$ of lactose broth (to make a 1:10 dilution). Then 1:100, 1:1000, and 1:10000 dilutions were prepared by adding saline. $0.5 \mathrm{~mL}$ of all dilutions were cultured on nutrient agar media. Also, $0.5 \mathrm{~mL}$ dilutions of 0.1 and 0.01 were cultured on MacConkey agar and Sabouraud's dextrose agar [18].

Table 1: Isolated bacteria and fungi from 62 contaminated ostrich eggshells.

\begin{tabular}{|l|c|}
\hline \multicolumn{1}{|c|}{ Microorganism } & $\begin{array}{c}\text { Number of Isolation from the Ostrich } \\
\text { Eggs (\% of whole) }\end{array}$ \\
\hline Bacteria & $1(1.6 \%)$ \\
\hline Actinomycete & $1(1.6 \%)$ \\
\hline Escherichia coli & $1(1.6 \%)$ \\
\hline Gram-negative coccobacillus & $46(74.0 \%)$ \\
\hline Gram-positive bacilli & $3(4.8 \%)$ \\
\hline Klebsiella spp. & $2(3.2 \%)$ \\
\hline Micrococcus spp. & $1(1.6 \%)$ \\
\hline Staphylococcus epidermidis & $1(1.6 \%)$ \\
\hline Fungi & $6(9.6 \%)$ \\
\hline Allscheria sp. & $3(4.8 \%)$ \\
\hline Alternaria spp. & $3(4.8 \%)$ \\
\hline Aspergillus flavus & $1(1.6 \%)$ \\
\hline Aspergillus nidulans & $6(9.6 \%)$ \\
\hline Curvularia spp. & $17(27.4 \%)$ \\
\hline Helminthosporium spp. & $4(6.4 \%)$ \\
\hline Mucor spp. & $2(3.2 \%)$ \\
\hline Penicillium spp. & $2(3.2 \%)$ \\
\hline Pullularia spp. & $2(3.2 \%)$ \\
\hline Rhodotorula spp. & $17(27.4 \%)$ \\
\hline Scopulariopsis spp. & \\
\hline Yeast & \\
\hline
\end{tabular}

Table 2: Isolated bacteria from the cloaca of seven newly hatched chicks and a mature female ostrich*.

\begin{tabular}{|l|c|c|}
\hline \multicolumn{1}{|c|}{ Individual } & MacConkey Agar & $\begin{array}{c}\text { Salmonella-Shigella } \\
\text { Agar }\end{array}$ \\
\hline 1. Chick & Neg. & Neg. \\
\hline 2. Chick & Neg. & Neg. \\
\hline 3. Chick & E. coli & E. coli \\
\hline 4. Chick & E. coli & E. coli \\
\hline 5. Chick & E. coli & Klebsiella oxytoca \\
\hline 6. Chick & Neg. & Neg. \\
\hline 7. Chick & Neg. & Neg. \\
\hline *8. Mature Female Ostrich & E. coli & $\begin{array}{l}\text { Enterobacter } \\
\text { agglomerans }\end{array}$ \\
\hline
\end{tabular}

Neg: Negative 


\section{Sampling of water}

Sampling was done to investigate the microbial contamination of the farm water. One sample was transferred to the laboratory to measure $\mathrm{pH}$ and water hardness. To identify the microbial contamination of farm water, MacConkey agar, blood agar, Sabouraud's dextrose agar, and nutrient agar culture media were used [19].

\section{Microbial cultures}

After sampling, they were transferred to the Laboratory of Department of Microbiology, Razi Vaccine and Serum Production Research Institute (Karaj-Iran) and microbial cultures were used to determine the type of organisms. The aerobic culture in an atmosphere of $5 \%$ carbon dioxide at $37^{\circ} \mathrm{C}$ overnight; and anaerobic culture incubated in a Microflow Anaerobic System cabinet providing an atmosphere of $10 \%$ carbon dioxide, $10 \%$ hydrogen and $80 \%$ nitrogen at $37^{\circ} \mathrm{C}$ for $48 \mathrm{~h}$.

Nutrient agar is a culture medium which is used for the cultivation of microbes supporting the growth of a wide range of non-fastidious organisms that can grow variety types of bacteria and fungi. It contains many nutrients needed for bacterial growth. Blood agar is used to culture those bacteria or microbes that do not grow quickly, such as Streptococcus pneumonia and Neisseria species. It detects and differentiates hemolytic bacteria, especially Streptococcus species, and is a differential media for the detection of hemolysis by cytolytic toxins secreted by some bacteria, such as certain strains of Bacillus, Streptococcus, Enterococcus, Staphylococcus, and Aerococcus. Sabouraud's dextrose agar is appropriate for cultivating dermatophytes and other types of fungi and filamentous bacteria, such as Nocardia. MacConkey agar is a selective and differential culture medium for bacteria designed to selectively isolate Gram-negative and bacilli and differentiate them based on lactose fermentation. PPLO agar contains beef heart infusion and peptone to supply nutrients required for the growth of pleomorphic, filterable, fastidious microorganisms which also lack a rigid cell wall such as mycoplasmas. Salmonella-Shigella agar is a selective and differential medium for the isolation, cultivation and differentiation of Salmonella spp. and some strains of Shigella spp. The survey of the colonies was performed using bacteriological method $[20,21]$.

\section{Statistical method}

The McNemar's test was used to investigate the effect of disinfection on reducing microbial contamination of ostrich eggs. The result was compared with the values of the Chi-squared table and $\mathrm{P}<0.05$ was considered to be significant [22].

\section{Results}

None of the tested ostrich eggs or egg-shells were microbe-free. They showed a wide range of microbial contaminations (Table 1). Forty-six eggs were contaminated with Gram-positive bacilli. There were few cases of contamination with some other bacteria, such as: Klebsiella spp. in 3 eggs; Micrococcus spp. in 2 eggs; E. coli, Staphylococcus epidermidis, Gram-negative coccobacillus, and Actinomycete each in an egg. The recognized fungi were as follows: Mucor spp. and yeast each in 17 eggs; Alternaria spp. and Helminthosporium spp. each in 6 eggs; Penicillium spp. in 4 eggs; Aspergillus flavus and Aspergillus nidulans each in 3 eggs; Rhodotorula spp., Pullularia spp. and Scopulariopsis spp. each in 2 eggs; and Allscheria and Curvularia spp. each in an egg.

Sampling of the cloaca showed that none of the birds was infected with Salmonella, and most of the contamination was due to Escherichia coli. One case of Klebsiella oxytoca contamination was detected in one of the chicks. Swap cloaca from a mature female ostrich that indicated by number 8, presented Enterobacter agglomerans and E. coli (Table 2).

In the content of five infertile ostrich eggs, fungi were detected (i.e. Mucor spp. and Helminthosporium spp.), but not any bacteria (Table 3).

Gram-positive bacilli, Rhodotorula spp., Staphylococcus epidermidis and Gram-positive cocci in the lungs; Helminthosporium spp. and Gram-positive bacilli in the liver; Gram-positive bacilli, Gram-positive cocci, and Aspergillus nidulans in the large intestine; Gram-positive bacilli in eyes; and not any infection in the yolk sac and heart of dead embryos were detected (Table 4).

Gram-positive bacilli, Alternaria spp. and Mucor spp. from setter machines; Gram-positive bacilli and Helminthosporium spp. from hatcher machine; Gram-positive bacilli, Mucor spp., Helminthosporium spp. and Aspergillus nidulans from setter room; Gram-positive bacilli, Mucor spp. and Alternaria spp. from hatcher room; Gram-positive bacilli, Mucor spp. and Helminthosporium spp. from air inlet duct; and Gram-positive bacilli, Alternaria spp. and Penicillium spp. from air outlet duct were isolated (Table 5).

Bacillus spp., Klebsiella spp., E. coli, and Mucor spp. from alfalfa were isolated. Gram-positive bacilli and yeast in soybean meal; Gramnegative Coccobacillius and Mucor spp. in wheat bran; Gram-positive bacilli, Mucor spp., Helminthosporium spp., Aspergillus nidulans, and Scopulariopsis spp. in bone meal; Mucor spp. and Gram-positive bacilli in corn; Mucor spp., Rhodotorula spp., and Gram-negative Coccobacillius in barley; and Mucor spp., Bacillus spp., and Klebsiella spp. in mixed diet were found (Table 6).

Drinking water of the farm was free of microbial contamination. The degree of water hardness, alkalinity, and $\mathrm{pH}$ was $217 \mathrm{ppm}, 113$ ppm, and 8 , respectively.

Disinfection with formaldehyde gas showed a significant impact on the reduction of the bacterial and fungal load in nutrient agar and Sabouraud's agar $(\mathrm{P}<0.05)$. These results indicate that disinfection with formaldehyde gas is useful when the rate of microbial contamination is high (Table 7).

\section{Discussion and Conclusion}

Microbial contamination can transmit vertically or horizontally from breeders to eggs. In the vertical route, bacteria may be colonized in ovaries or oviducts and the eggs become infected. Although in our study, the type of isolated microbes in the mature female's cloaca and content of infertile eggs was not similar, but, the risk of transmission of microbial contamination from the reproductive system of female birds to eggs is very high. For example, egg-shells can be contaminated with Salmonella trough the oviduct or faecal carriage [23]. In the horizontal rout, the microbes can contaminate the egg-shell through the environment, such as faecal material or dust and infect the membranes and yolk [9]. Due to the formation of spores and drought resistance, Gram-positive rods can dominate the egg-shell microflora. It has been reported that some opportunistic germs, such as some fungi, Grampositive cocci, Gram-negative enteric, and Gram-negative fermenters can infect egg contents [24,25]. If the environmental conditions are suitable for microbial growth, microbes can multiply rapidly in freshly laid eggs and penetrate the egg-shell through the pores. Eventually, this situation can lead to embryos' death and a reduction in the hatching rate [10].

In a scientific report study, Bacillus spp., Staphylococcus spp., Klebsiella spp., Escherichia coli, and Proteus spp. were isolated from 
Klebsiella spp., Escherichia coli, and Proteus spp. were isolated from twelve dead embryos of the ostrich [26]. Staphylococcus spp. also was found in dead embryos in the present study, and Bacillus spp., Klebsiella spp., and Escherichia coli existed on the egg-shells of our research. All microbes that exist in table 4 have also been reported in table 1. So it can be concluded that the contamination through the eggshell has penetrated into the eggs. Gram-positive bacilli that have been detected in the lung, liver, intestine and the eyes of the dead embryos also have been isolated in almost all areas of the farm, such as feed ingredients (Table 5), incubation room, setter and hatcher machines and air inlet and air outlet ducts of incubation rooms (Table 6). The presence of contaminants in infertile eggs can be a reason for the high rate of early embryonic mortality in the ostrich eggs [7].

Table 3: Isolated microbes from the content of five infertile ostrich eggs.

\begin{tabular}{|c|c|c|l|c|c|}
\hline No. of Ostrich Eggs/Culture media & MacConkey agar & Blood agar & Sabouraud's dextrose agar & Nutrient agar & PPLO agar \\
\hline 1 & Neg. & Neg. & Neg. & Neg. & Neg. \\
\hline 2 & Neg. & Neg. & Helminthosporium spp. & Neg. & Neg. \\
\hline 3 & Neg. & Neg. & Mucor spp. & Neg. & Neg. \\
\hline 4 & Neg. & Neg. & Neg. & Neg. & Neg. \\
\hline 5 & Neg. & Neg. & Helminthosporium spp. & & Neg. \\
\hline
\end{tabular}

Neg: Negative

Table 4: Isolated microbes from different organs of the two dead embryos.

\begin{tabular}{|l|c|c|c|c|c|c|}
\hline $\begin{array}{c}\text { Organ/Culture } \\
\text { media }\end{array}$ & MacConkey agar & Blood agar & $\begin{array}{c}\text { Sabouraud's dextrose } \\
\text { agar }\end{array}$ & Nutrient agar & PPLO Agar & $\begin{array}{c}\text { Salmonella- } \\
\text { Shigella agar }\end{array}$ \\
\hline $\begin{array}{l}\text { Lung } \\
\text { Neg:Negative }\end{array}$ & Neg. & $\begin{array}{c}\text { Gram-positive } \\
\text { bacilli }\end{array}$ & Rhodotorula spp. & $\begin{array}{c}\text { Staphylococcus epidermidis, } \\
\text { Gram-positive bacilli, Gram- } \\
\text { positive cocci }\end{array}$ & Neg. & Neg. \\
\hline Liver & Neg. & Neg. & Helminthosporium spp. & Gram-positive bacilli & Neg. & Neg. \\
\hline Large Intestine & Neg. & $\begin{array}{c}\text { Gram-positive } \\
\text { bacilli }\end{array}$ & Aspergillus nidulans & $\begin{array}{c}\text { Gram-positive bacilli, Gram- } \\
\text { positive cocci }\end{array}$ & Neg. & Neg. \\
\hline Eyes & Neg. & Neg. & Neg. & Gram-positive bacilli & Neg. & Neg. \\
\hline Yolk Sac & Neg. & Neg. & Neg. & Neg. & Neg. & Neg. \\
\hline Heart & Neg. & Neg. & Neg. & Neg. & Neg. & Neg. \\
\hline
\end{tabular}

Table 5: Isolated microbes from different parts of the incubation room.

\begin{tabular}{|l|c|c|c|c|}
\hline $\begin{array}{c}\text { Sampling location /Culture } \\
\text { media }\end{array}$ & MacConkey agar & Blood agar & Sabouraud's dextrose agar & Nutrient agar \\
\hline Setter machine (swab) & Neg. & Neg. & Mucor spp. & Neg. \\
\hline Hatcher machine (swab) & Neg. & Gram-positive bacilli & Helminthosporium spp. & Gram-positive bacilli \\
\hline Setter machine (Petri dish) & Neg. & Gram-positive bacilli & Alternaria spp. & Gram-positive bacilli \\
\hline Hatcher machine (Petri dish) & Neg. & Neg. & Helminthosporium spp. & Gram-positive bacilli \\
\hline Setter room & Neg. & Gram-positive bacilli & $\begin{array}{c}\text { Mucor spp., Helminthosporium spp., } \\
\text { Aspergillus nidulans }\end{array}$ & Gram-positive bacilli \\
\hline Hatcher room & Neg. & Gram-positive bacilli & Mucor spp., Alternaria spp. & Gram-positive bacilli \\
\hline Air inlet duct & Neg. & Gram-positive bacilli & Mucor spp., Helminthosporium spp. & Gram-positive bacilli \\
\hline Air outlet duct & Neg. & Gram-positive bacilli & Alternaria spp., Penicillium spp. & Gram-positive bacilli \\
\hline
\end{tabular}

Neg: Negative

Table 6: Isolated germs from feed ingredients.

\begin{tabular}{|l|c|c|}
\hline \multicolumn{1}{|c|}{ Feed Items/Culture media } & Bacteria & Fungi \\
\hline Soybean meal & Gram-positive bacilli & Mucor spp. \\
\hline Alfalfa & Bacillus spp., E. coli, Klebsiella spp. & Mucor spp. \\
\hline Wheat bran & Gram-negative coccobacillus & Mucor spp., Helminthosporium spp., Aspergillus nidulans, \\
\hline Bone meal & Gram-positive bacilli & Mucor spp. \\
\hline Corn & Gram-positive bacilli & Mucor spp., Rhodotorula spp. \\
\hline Barley & Gram-negative coccobacillus & Mucor spp. \\
\hline Mixed diet & Bacillus, Klebsiella spp. & M \\
\hline
\end{tabular}


Table 7: Microbial culture results of 10 ostrich eggs before and after disinfection with formaldehyde gas.

\begin{tabular}{|c|c|c|c|c|c|}
\hline \multirow[b]{2}{*}{$\begin{array}{c}\text { Microbial status of egg-shells before/ } \\
\text { after disinfection* }\end{array}$} & \multicolumn{4}{|c|}{ Culture media } & \multirow[b]{2}{*}{ PPLO agar } \\
\hline & MacConkey agar & Blood agar & Sabouraud's agar & Nutrient agar & \\
\hline Negative/negative & 6 & 1 & 2 & 0 & 7 \\
\hline Negative/positive & 0 & 1 & 0 & 0 & 0 \\
\hline Positive/negative & 4 & 7 & 6 & 8 & 3 \\
\hline Positive/positive & 0 & 1 & 2 & 2 & 0 \\
\hline$\chi^{2 * *}$ & 2.25 & 3.12 & 4.16 & 6.12 & 1.33 \\
\hline$P$-value & 0.13 & 0.07 & 0.04 & 0.01 & 0.24 \\
\hline
\end{tabular}

*Positive: Growth; Negative: No Growth

**McNemar chi-squared statistic with Yates correction of $1.0 ; \chi^{2}$ value exceeds the table value of 3.841 (at 1 degree of freedom and an alpha level of $0.05)$

twelve dead embryos of the ostrich [26]. Staphylococcus spp. also was found in dead embryos in the present study, and Bacillus spp., Klebsiella spp., and Escherichia coli existed on the egg-shells of our research. All microbes that exist in table 4 have also been reported in table 1 . So it can be concluded that the contamination through the eggshell has penetrated into the eggs. Gram-positive bacilli that have been detected in the lung, liver, intestine and the eyes of the dead embryos also have been isolated in almost all areas of the farm, such as feed ingredients (Table 5), incubation room, setter and hatcher machines and air inlet and air outlet ducts of incubation rooms (Table 6). The presence of contaminants in infertile eggs can be a reason for the high rate of early embryonic mortality in the ostrich eggs [8].

Deeming DC [9] examined microbial contaminations in ostrich eggs. He reported six cases of fungal contamination in ostrich eggshells that four of them were found in the present study. Previous studies indicated that the role of bacteria is more prominent in the contamination of eggs than fungi. However, it is stated that the addling of eggs strongly related to the attendance of fungi on egg-shells [28]. Fungal spores are almost present everywhere. Fungi can cause a variety of infectious diseases and intoxications due to their high numbers and prevalence and rapid spore release. Eggs have limited chemical defense against fungi (e.g. no chitinases). Fungi can break down the shell cuticle. As a result, the egg-shell pores would be accessed for bacteria and they can quickly enter into the eggs [11,29].

Some papers reported that ostrich eggs do not have a cuticle layer (Deeming, 1995), while some researchers have reported its existence [30]. Therefore, because of this contradiction, it is necessary to minimize the probability of contamination of eggs with preventive methods. Studies conducted under laboratory conditions have shown that the presence of water is necessary for penetration of microbes into the egg-shells. Because the moisture leads to the proliferation of bacteria on the egg-shells and by penetrating the shell pores, it acts as a medium for the transmission of microbes [11,29]. Thus the nest of ostriches should be well dry, be covered with a grainy litter, and dust should be cleaned regularly.

In the farm under our study, the eggs were collected after being laid and the environment of the farm was usually kept clean. Unfortunately, the disinfection of in incubated eggs was not performed and the disinfection of incubation rooms and incubator machines were only administered at the beginning of the breeding season, and no vaccination was done.

Due to increasing the diffusion resistance in the pores of eggshells and reducing gaseous exchange, the washing of eggs is not recommended. Also, if the temperature of the disinfectant solution is lower than the temperature of the egg, the volume of the egg content reduced. This causes a negative pressure and a vacuum that moves bacteria to the internal contents of the egg through the pores of the shell, and the embryo becomes infected [7,30]. Since the usefulness of using a mixture of permanganate-potassium formalin to disinfection of ostrich eggs is questionable due to its strong oxidizing properties [7], our results showed this method of disinfection was beneficial for the reduction of microbial load of the egg-shell in a high rate contamination. But in a low rate of contamination it was not very effective and can be ignored with some measures and practices, such as implementing sanitation and hygiene e.g. quick collection of eggs [31], the maintenance of nest hygiene [32], carefully gathering and wiping the eggs with a dry cloth, and holding the eggs with sterile toweling [33].

Average hatchability of incubated eggs in the commercial ostrich farms have ranged from $37.5 \%$ to $61.8 \%$ [6]. In commercial farms, even a small increase in hatchability leads to more economic benefit, so everything should be done to its improvement. Therefore, due to the role of microbial contamination in the reduction of hatchability and the uncertainty about the presence of cuticle in ostrich eggs, rigid standards of sanitation must be maintained in everywhere in the ostrich farm.

\section{Acknowledgement}

We thank the manager and staff of the Mohases ${ }^{\oplus}$ ostrich commercial farm for their assistance. The authors gratefully acknowledge the Razi Vaccine and Serum Production Research Institute for their cooperation and laboratory facilities.

\section{References}

1. Abd El-Hack ME, Hurtado CB, Toro DM, Alagawany M, Abdelfattah EM, et al. (2019) Fertility and hatchability in duck eggs. World's Poult Sci J 75: 599-608.

2. King'Ori AM (2011) Review of the factors that influence egg fertility and hatchability in poultry. Int J Poult Sci 10: 483-492.

3. Elibol O, Peak SD, Brake J (2002) Effect of flock age, length of egg storage, and frequency of turning during storage on hatchability of broiler hatching eggs. Poult Sci 81: 945-950.

4. Yassin H, Velthuis AG, Boerjan M, van Riel J, Huirne RB (2008) Field study on broiler eggs hatchability. Poult Sci 87: 2408-2417.

5. Khosravi AR, Shokri H, Ziglari T, Naeini AR, Mousavi Z, et al. (2008) Outbreak of severe disseminated Aspergillosis in a flock of ostrich (Struthio camelus). Mycoses 51: 557-559. 
6. Bronneberg RG, Taverne MA (2003) Ultrasonography of the female reproductive organs in farmed ostriches (Struthio camelus spp.). Theriogenology 60: 617-633.

7. Cooper RG (2001) Handling, incubation, and hatchability of ostrich (Struthio camelus var. domesticus) eggs: a review. J Appl Poult Res 10: 262-273.

8. Deeming DC (1995) Factors affecting hatchability during commercial incubation of ostrich (Struthio camelus) eggs. British Poult Sci 36: 51-65.

9. Bruce J, Drysdale EM (1994) Trans-shell transmission. In: Board RG, Fuller R (eds) Microbiology of the Avian Egg. Chapman and Hall, London 63-91.

10. Cook MI, Beissinger SR, Toranzos GA, Arendt WJ (2005) Incubation reduces microbial growth on eggshells and the opportunity for trans-shell infection. Ecol Lett 8: 532-537.

11. Board RG, Loseby S, Miles VR (1979) A note on microbial growth on hen egg shells. British Poult Sci 20: 413-420.

12. Dzoma BM (2010) Some Factors Affecting Fertility and Hatchability in the Farmed Ostrich: A Review. J Anim Vet Adv 9: 229-239.

13. Leuthold W (1977) Notes on the breeding biology of the ostrich Struthio camelus in Tsavo East National Park, Kenya. Ibis 119: 541544.

14. Berrang ME, Cox NA, Bailey JS (1995) Measuring Air-Borne Microbial Contamination of Broiler Hatching Cabinets. J Appl Poult Res 4: 8387

15. Khan MA, Ashfaque M, Hussain I (1999) Bacteriology of Dead-inShell Broiler Embryos and Antibiotic Sensitivity of the Isolates. Pak J Biol Sci 2: 442-444.

16. Rezaei Far A, Peighambari SM, Sadrzadeh A, Askari Badouei M (2013) Bacterial contamination of dead-in-shell embryos in ostrich hatcheries and antimicrobial resistance patterns of isolated Escherichia coli. Iran J Vet Med 7: 169-175.

17. Afriyani A, Darmawi D, Fakhrurrazi F, Manaf ZH, Abrar M, et al. (2016) Isolation of Salmonella sp. in feces of broiler chicks at Ulee Kareng Market Banda Aceh. J Med Vet 10: 74-76.

18. Danbappa AAR, Alhassan KA, Shah MM (2018) Isolation and identification of microbial contaminants associated with commercial poultry feeds. Journal of Applied and Advanced Research 3: 142147.

19. Walker JT, Bradshaw DJ, Bennett AM, Fulford MR, Martin MV, et al. (2000) Microbial biofilm formation and contamination of dental-unit water systems in general dental practice. Appl Environ Microbiol 66: 3363-3367.
20. Swayne DE, American Association of Avian Pathologists (1998) A laboratory manual for the isolation and identification of avian pathogens. $4^{\text {th }}$ Edition, The American Association of Avian Pathologists, Pennsylvania, USA 4-16.

21. Quinn PJ, Markey BK, Carter ME, Donnelly WJ, Leonard FC (2001) Veterinary Microbiology and Microbial Disease. $1^{\text {st }}$ Edition, Blackwell Science, Oxford 43-122.

22. Fagerland MW, Lydersen S, Laake $P$ (2013) The McNemar test for binary matched-pairs data: mid-p and asymptotic are better than exact conditional. BMC Med Res Methodol 13: 91.

23. Humphrey TJ (1994) Contamination of eggs with potential human pathogens. In: Board RG, Fullar R (eds) Microbiology of the avian egg. Chapman and Hall, London 93-116.

24. Kozlowski S, Malysko E, Pinowski J, Kruszewicz A (1989) The effect of microorganisms on the mortality of house sparrow (Passer domesticus) and tree sparrow (Passer montanus) embryos. Intecol Slupsk Poland 1: 121-128.

25. Houston CS, Saunders JR, Crawford RD (1997) Aerobic bacterial flora of addled raptor eggs in Saskatchewan. J Wild Dis 33: 328-331.

26. Jahantigh M (2010) Bacteriological study of dead-in-shell embryos of ostrich, scientific report. J Vet Res 11: 88-90.

27. Cook MI, Beissinger SR, Toranzos GA, Rodriguez RA, Arendt WJ (2003) Trans-shell infection by pathogenic micro-organisms reduces the shelf life of non-incubated bird's eggs: a constraint on the onset of incubation? Proc Biol Sci 270: 2233-2240.

28. Board RG, Halls NA (1973) The cuticle: a barrier to liquid and particle penetration of the shell of the hen's egg. Br Poult Sci 14: 69-97.

29. Richards PDG, Botha A, Richards PA (2002) Morphological and histochemical observations of the organic components of ostrich eggshell. J S Afr Vet Assoc 73: 13-22.

30. Tøien $\varnothing$, Paganelli CV, Rahn H, Johnson RR (1988) Diffusive resistance of avian eggshell pores. Respir Physiol 74: 345-354.

31. Button C, Moon D, Turner D (1994) Increasing the hatchability of ostrich eggs. Aust Ostrich Assoc J 27: 18-23.

32. Deeming DC (1996) Production, fertility and hatchability of ostrich (Struthio camelus) eggs on a farm in the United Kingdom. Anim Sci 63: 329-336.

33. Cooper RG (2000) Treat ostrich eggs with care. World Poult 16: 33. 